Thorax (1971), 26, 99.

\title{
Acute orthotopic transplantation of hearts stored for 72 hours
}

\author{
E. PROCTOR, G. MATTHEWS, and J. ARCHIBALD \\ Department of Surgical Sciences, Royal College of Surgeons of England, 35/43 Lincoln's Inn Fields, \\ London WC2A 3PN
}

\begin{abstract}
Using a storage method based on hypothermic $\left(4^{\circ} \mathrm{C}\right)$ perfusion with a water-based asanguinous solution the dog heart has been preserved for up to 72 hours in a viable condition. The ultimate functional test of the viability of such hearts is orthotopic transplantation. Seven of eight dog hearts stored for $\mathbf{7 2}$ hours were able to support the recipient circulation in a stable manner after acute orthotopic transplantation. The donor hearts maintained a mean arterial pressure of 70-100 $\mathrm{mmHg}$, left atrial pressure 5-12 $\mathrm{cm} \mathrm{H}_{2} \mathrm{O}$, and maximum $\mathrm{dp} / \mathrm{dt}$ of the left ventricular pressure was $1,200-2,400 \mathrm{mmHg} / \mathrm{second}$. No myocardial stimulants were used. The results of 72 hours' hypothermic perfusion storage were superior to those of previously reported six hours' non-perfusion storage. A comment is made on the empirical nature of this field.
\end{abstract}

The storage of organs in a viable condition is central to many of the problems of organ transplantation. The more obvious and immediate benefits to be gained from such storage include elective rather than emergency surgery, the ability to transport the organ from the donor to the place best fitted to use it, and time to identify and make available the most suitable recipient. In the heart, the magnitude of the operation, the complexity of cardiopulmonary bypass, and the size of the operating team all render these benefits of even greater importance than in the kidney. Furthermore, the fact that there can be no return to the circulatory equivalent of dialysis should the heart be rejected places a premium on selection of the recipient with the closest possible tissue match, and this may require considerable time. But whereas the kidney has been stored in a viable condition for up to 72 hours (Belzer, Ashby, and Dunphy, 1967), storage of the heart has met with less success; to date the longest period that a heart has been stored in vitro and has retained sufficient viability to support the circulation after orthotopic transplantation is 24 hours (Feemster and Lillehei, 1969).

Some time ago we reported the first successful storage of dog hearts by hypothermic perfusion for 72 hours (Proctor and Parker, 1968). These hearts were not orthotopically transplanted but were attached to the femoral artery and vein of another dog, and were assessed for viability by recording the mechanical performance, electrical activity, and histology, and by comparison with control hearts that had not been stored. Although these hearts performed satisfactorily and were viable by these standards, without orthotopic transplantation we could not be sure that they were sufficiently viable to support the circulation. Consequently, when facilities became available we began orthotopic transplantation of the stored hearts. Functionally, the critical period for the orthotopically transplanted heart is immediately after transplantation, when cardiopulmonary bypass is discontinued. If the heart survives this period the outcome is determined by factors unrelated to initial viability, such as haemorrhage, infection, immunosuppression and rejection. As a preliminary, therefore, to a long-term programme involving immunosuppression and survival, we were concerned first to establish the performance of the stored hearts under conditions that involved none of these variables, and we have carried out acute orthotopic transplantation on a small group of these hearts in order to determine their capacity to support the circulation after being stored for 72 hours.

\section{METHOD}

The experiments were carried out on eight dogs weighing 19 to $30 \mathrm{~kg}$. The donor hearts weighed 150 to $250 \mathrm{~g}$. The technique of hypothermic $\left(4^{\circ} \mathrm{C}\right)$ 


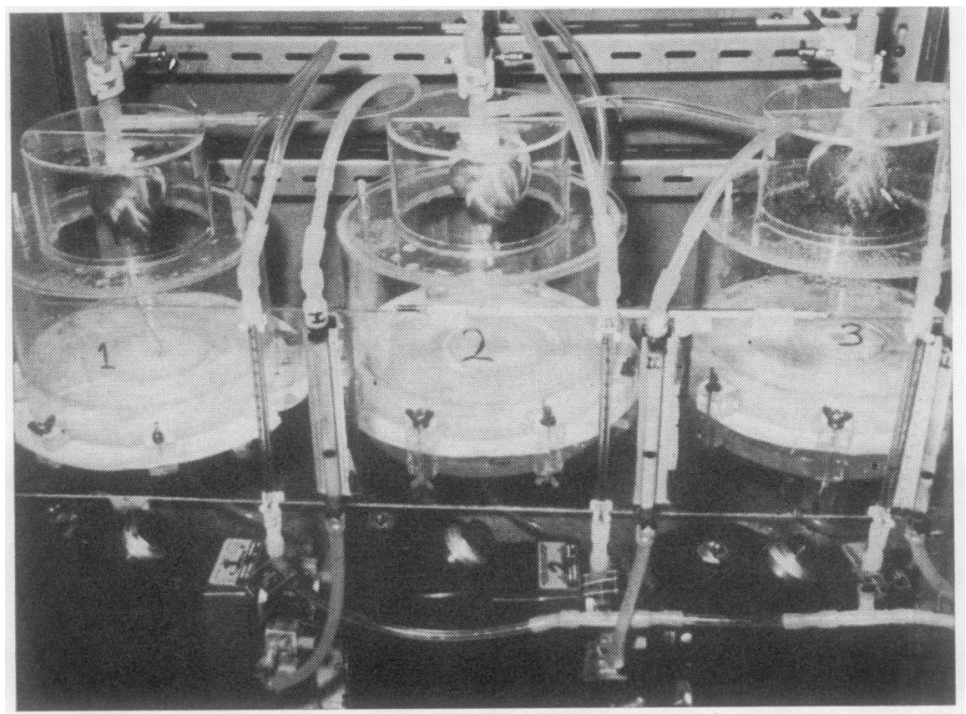

FIG. 1. Three separate hypothermic perfusion units containing hearts photographed through transparent door of a large refrigerator. The pots act as reservoir, oxygenator, and filter, thus simplifying the apparatus, a necessary feature if multiple units in a heart 'bank' are to be developed.

perfusion storage using an asanguinous solution was similar to that previously described (Proctor and Parker, 1968), but with the glass sinter method of continuous filtration replaced by disposable Sartorius ${ }^{1}$ cellulose nitrate filters of 8 micron pore size. A further change was the use of chlorpromazine $(15 \mathrm{mg} /$ litre) in the perfusate to prevent ventricular fibrillation during rewarming of the stored hearts. Figure 1 shows three such perfusion units in an experimental heart 'bank' within a large refrigerator. The Perspex pots act as reservoir, oxygenator, and filter, thus simplifying the apparatus, a necessary feature if multiple units in a heart 'bank' are to be developed. For convenience, and to avoid problems associated with the use of homologous blood in dogs (Gadboys, Jones, Slonim, Wisoff, and Litwak, 1963), cardiopulmonary bypass was by a total haemodilution method using a low-prime oxygenator of our own design (Proctor and de Bono, 1965). After the donor hearts had been inserted into the recipient the myocardium was rewarmed in situ by flushing the coronary vessels with fresh perfusate solution, minus the procaine and chlorpromazine, before opening the aortic clamp. Cardiopulmonary bypass was stopped a few minutes later and systemic arterial pressure, venous pressure, left atrial pressure, and maximum $\mathrm{dp} / \mathrm{dt}$ of the left ventricular pressure (as a measure of myocardial contractility) were recorded. Pacemaker leads were not inserted.

1Sartorius Membranfilter GMBH, Gottingen, Germany: agentsV. A. Howe and Co. Ltd., 88 Peterborough Road, London S.W.6

\section{RESULTS}

After insertion seven of the eight stored hearts developed a strong beat within several minutes of being rewarmed; the exception was a heart? inadequately flushed due to an error in the flushing technique. On stopping the cardiopulmonary? bypass, all seven of the rewarmed hearts werex able to support the circulation of the recipient $\frac{}{3}$ animal without recourse to myocardial stimulants. Post-bypass the systemic arterial pressure was in the range $70-100 \mathrm{mmHg}$ (mean), venous pressure $2-4 \mathrm{~cm} \mathrm{H}_{2} \mathrm{O}$, left atrial pressure $5-12 \mathrm{~cm} \mathrm{H}_{2} \mathrm{O}$, and the maximum rate of change of the left ventricu- $-\mathrm{D}$

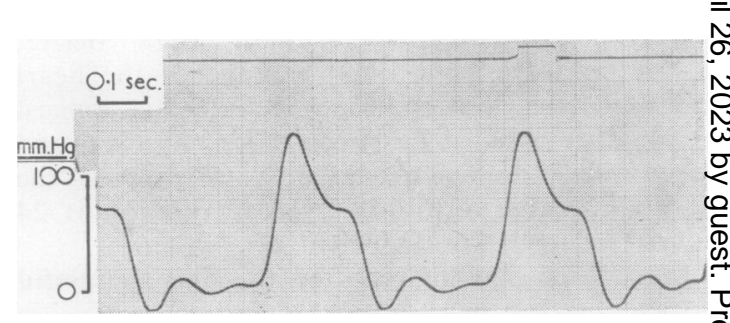

FIG. 2. Left ventricular pressure tracing of the bes 72-hour stored heart after orthotopic transplantation $\frac{}{\mathrm{D}}$ Maximum dp/dt LVP 2,400 $\mathrm{mmHg} /$ second without myo cardial stimulation. 
lar pressure $(\max . \mathrm{dp} / \mathrm{dt})$ was in the range 1,200 $2,400 \mathrm{mmHg} /$ second ; one of the best results in this respect is shown in Figure 2. The above results were all recorded in the absence of myocardial stimulation (noradrenaline, isoprenaline, calcium, or digitalis) since we were concerned in this series with measuring the performance of these stored hearts as a baseline study. It is a measure of the viability of these hearts that one of them survived a period of 15 minutes' ischaemic cardiac arrest at $37^{\circ} \mathrm{C}$ due to a coronary air embolism associated with removal of the left ventricular vent. This was the only occasion on which it was necessary to return to cardiopulmonary bypass; after. removal of the air embolus the heart was able to resume control of the circulation. Each experiment was discontinued after $1 \frac{1}{2}-2$ hours' stable control of the circulation.

\section{DISCUSSION}

The transplanted heart is a denervated organ, and being deprived of its endogenous noradrenaline is at a marked physiological disadvantage compared with the normal heart (Willman, Merjavy, Pennell, and Hanlon, 1967 ; Ebert, 1968 ; Linden, 1969). When to this insult is added a 10-minute period of ischaemic arrest during its removal from the donor, up to 1 hour without perfusion (albeit kept cold) during insertion, 3 to 4 hours of anaesthesia, and up to 2 hours of cardio-
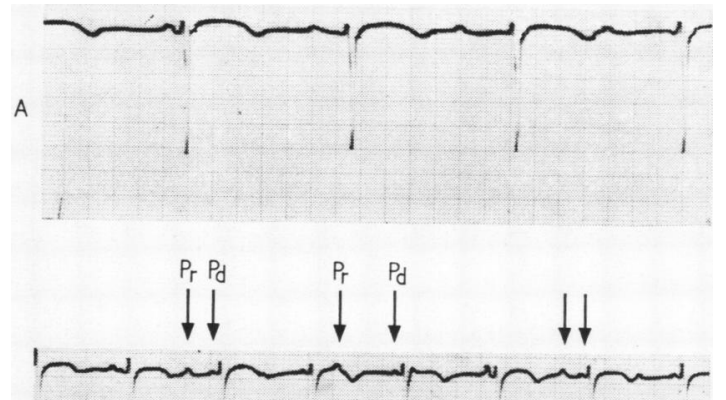

B

FIG. 3. Electrocardiogram (lead III) showing the development of sinus rhythm in heart stored for 72 hours and then orthotopically transplanted: $A, 10$ minutes off cardiopulmonary bypass, showing only the recipient $P$ wave; $B, 30$ minutes off bypass, showing both recipient $P$ wave $(P r)$ and donor $P$ wave $(P d)$. pulmonary bypass, it says much for the method of storage when a 72-hour heart will resume immediate control of the circulation after orthotopic transplantation. What is surprising is that it beats at all.

It is our impression that hearts stored for 72 hours by hypothermic perfusion perform better when orthotopically transplanted than comparable hearts flush-cooled in the same way but stored without perfusion at $4^{\circ} \mathrm{C}$ for 6 hours in the shortterm transport system previously described (Proctor and Matthews, 1970). This is more objectively shown in the increase in the $\max . \mathrm{dp} / \mathrm{dt}$ of the perfused hearts (mean of $1,550 \mathrm{mmHg} /$ second compared with $1,050 \mathrm{mmHg} /$ second in the 6-hour non-perfused hearts), and the more frequent and rapid return of sinus rhythm in the perfused hearts, a good example of which is shown in Figure 3. This point is worth making in view of the unique requirement that the heart must support the recipient circulation immediately after transplantation. Although convenient and simple, the use of non-perfusion methods (i.e., flushcooling only) for transporting the donor heart should be limited in the present state of our knowledge to periods of less than 6 hours.

A puzzling feature of this method of hypothermic perfusion is that such good results can be attained with a solution that is completely asanguinous, merely a balanced salt solution with added dextran 70 , hydrocortisone, procaine, and chlorpromazine. Viability after such prolonged perfusion with a solution devoid of a single organic component of plasma raises questions as to what is happening during tissue storage. We talk of 'metabolic inhibition', 'inhibition of oxidative phosphorylation', and 'interference with electron transport', but the fundamental question may be whether cell death in the absence of a normal nutritional milieu is necessarily an active process which may not take place if one can specifically prevent the leakage of autolytic enzymes; hence the popularity of such 'membrane stabilizers' as chlorpromazine and magnesium. Virtually nothing is known of the physiology and biochemistry of this state of near suspended animation in the region of $4^{\circ} \mathrm{C}$, and each group of investigators appears to have a different means of attaining it. Until we can unearth some of the underlying principles, organ storage is likely to continue as a purely empirical activity.

We are indebted to Lord Brock for his support and encouragement in this work. 
We should also like to thank J. Manders and T. Jones for able assistance.

The Medical Research Council kindly provided financial support for this study.

We are also grateful to the British Heart Foundation for their support in this work.

\section{REFERENCES}

Belzer, F. O., Ashby, B. S., and Dunphy, J. E. (1967). 24-hour and 72-hour preservation of canine kidneys. Lancet, 2, 536.

Ebert, P. A. (1968). The effects of norepinephrine infusion on the denervated heart. J. cardiovasc. Surg. (Torino), 9, 414.

Feemster, J. A., and Lillehei, R. C. (1969). Hypothermichyperbaric pulsatile perfusion for preservation of the canine heart. Transplantation Proc., 1, 138.
Gadboys, H. L., Jones, A. R., Slonim, R., Wisoff, G. and Litwak, R. S. (1963). The homologous blood syndrome. III. Influence of plasma, buffy coat and rec. cells in provoking its manifestations. Amer. J. Cardiol. 12, 194.

Linden, R. J. (1969). Speculation on the function of the transplanted heart. Amer. Heart J., 77, 830.

Proctor, E., and de Bono, A. H. (1965). A low primin $\overrightarrow{\mathbf{b}}$ volume oxygenator for bloodless priming in cardio pulmonary bypass. Thorax, 20, 540 .

- and Matthews, G. (1970). A simple method for the short term ( 6 hours) transport of the dog heart prior to orthotopic transplantation. Thorax, 25, 477.

- and Parker, R. (1968). Preservation of the isolate heart for 72 hours. Brit. med. J., 4, 296.

Willman, V. L., Merjavy, J. P., Pennell, R., and Hanlon, C. Re (1967). Response of the autotransplanted heart to blood volume expansion. Ann. Surg., 166, 513. 